\title{
A Collaborative Approach to Instructional Development
}

Carolyn Heacock, Summer Peixoto, Melissa Stamer Peterson, Baiba Šedriks, and Marina Greene

Lecturers

Applied English Center
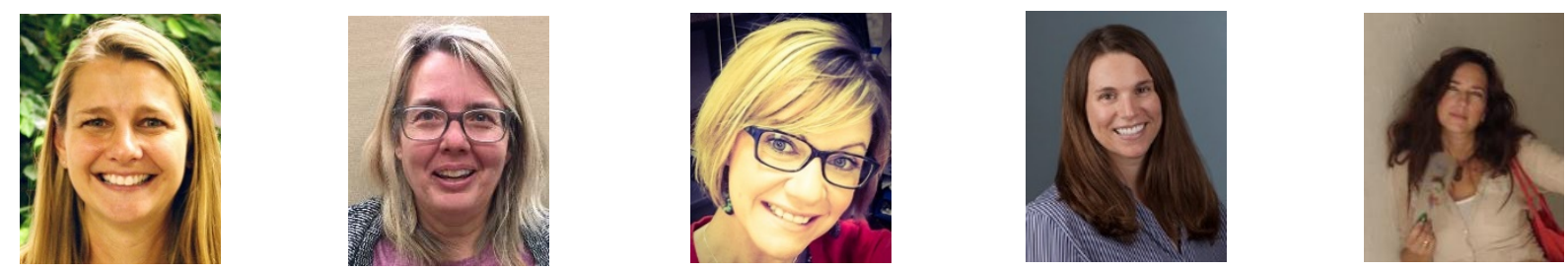

\section{Introduction}

Regardless of how long instructors have been in the classroom, they should continue to focus on improving their instructional practices. Being observed by others and observing others can inform teaching practices and assist in professional development. In the Applied English Center (AEC), the ESL center for the University of Kansas, formal observation by course coordinators is the primary instructional development tool used to provide instructors with targeted feedback about their teaching. However, because these formal observations are also evaluative in nature, they can create angst in instructors, making it difficult to view this tool as an opportunity to improve. Another tool instructors have used to improve their teaching is observing peers with the goal of seeing how colleagues approach their teaching. Those who have been able to observe their colleagues for this purpose have found this to be an effective (and less stressful) method for improving their own teaching; however, many instructors in the AEC have not had this opportunity to observe one another to learn from one another.

Several years ago, the AEC entered into a partnership with a pathway program to provide English for Academic Purposes (EAP) courses for recruited students. There are several differences between the EAP component in this program and our traditional intensive English program, one of which is that the EAP courses for the pathway program do not have course coordinators. Because of this, no one is formally assigned to observe the EAP instructors teach in this pathway program. Initially, this was a welcomed change because it freed instructors from the anxiety that can be felt during formal observations; however, after a short time, 
instructors missed the formative feedback they had previously received from their coordinators. It was out of this desire for continued professional growth that the Collaborative Instructional Development (CID) process was developed.

The CID team desired to create a peer observation process that is collaborative and non-threatening, that promotes self-reflection, and that is mutually beneficial for the one being observed and the observer. When peer observations are used as a tool for exchanging ideas and sharing teaching techniques, they can have a positive impact on the quality of teaching and student learning (Teachers Observing Teachers: A Professional Development Tool for Every School, 2017). Using ideas gleaned from this article and the peer observation process used at Cornell University (Peer Review of Teaching, 2012), the CID team created a four-step process that encourages each instructor to think critically about his or her own teaching, set goals, and assess individual progress. Observers are encouraged to ask clarifying questions designed to urge instructors to think deeply about their own teaching and to learn more from the person they observe. Both participants are encouraged to consider ways they can fine-tune their own teaching. Neither the observer nor the instructor has the role of evaluating the other; rather, they are both encouraged to engage in dialogue about effective instructional techniques.

\section{The CID Process}

The four steps to this process include a pre-observation meeting, a classroom visit, a post-observation meeting and a written summary by both the observer and instructor to be included in their personnel files. During the pre-observation meeting, the instructor discusses the lesson that is going to be taught. The instructor explains how this lesson fits in with the broader scope of the semester, what student learning outcome (SLO) will be addressed, what activities will be used, how student performance will be measured in class, and what aspect of teaching the instructor is currently developing or refining. The observer's role in the meeting is to listen carefully, ask clarifying questions, and consider insights he or she can gain from the instructor. This meeting allows the instructor to clarify the purpose of the lesson and the rationale behind each activity. Having to verbalize how a lesson fits into the goals of a class and how classroom activities help students learn the 
content encourages instructors to reflect on why they do what they do and causes them to evaluate their own teaching, which is one of the primary goals of this approach to professional development.

The second step is the observation. During the observation, the observer pays close attention to how the instructor addresses the SLO, how the students respond to the instruction, and what the instructor does to make progress on the teaching aspect he or she is working to improve. Instead of writing down evaluative comments, such as, "this lesson was effective," the observer makes notes on what the instructor and students say and do. It is not necessary for the observer to record every second of class, but rather to focus on the instructional goal and teaching aspect the instructor is working on. In addition to making notes that will inform the post-observation discussion, the observer should also be attuned to approaches that can inform the observer's teaching. This is one of the main benefits of observing a colleague - being able to learn from someone else.

The third step of this collaborative process is the post-observation meeting. In the AEC, traditional postobservation meetings are led by the coordinator. The instructors often attend this meeting with one question in mind, "How does my coordinator think I did?" The coordinator provides evaluative comments about the instructor's teaching with supporting evidence and suggestions for improvement. While this feedback is informative and helpful, it can also be stress-inducing because, from the instructor's perspective, the "power" is in the hands of the coordinator. The perception is often that the coordinator's assessment of the teaching is what ultimately matters most.

One of the primary differences between the AEC’s traditional approach to classroom observations and this new collaborative approach is that the instructor has the primary responsibility to evaluate his or her own teaching with this new approach. The instructor thinks critically about the class prior to the post-observation meeting by reflecting on questions like these:

- What went well in class? What caused that aspect of class to be successful?

- How well did students learn what I wanted them to learn? What was evidence of that learning?

- What progress did I make on my teaching goal?

- What could I do to hone my skills even further? 
During the post-observation meeting, the instructor should lead with his or her perceptions about the class, citing specific behaviors or words that inform these perceptions. Focusing on specific behaviors and words instead of personal feelings informs teaching and allows instructors to evaluate what causes or detracts from learning.

The observer's primary roles in this meeting are to listen carefully and ask clarifying questions to support the instructor through this self-reflection process. Before the meeting, the observer should also consider questions such as:

- What did the instructor do to teach toward the SLO?

- What did the instructor do to address the personal teaching goal?

- How did the students respond to the teaching?

- What evidence was there of student learning?

At this point, the observer can ask clarifying questions and then share his or her perspective. During this discussion, both participants can give and receive advice about effective teaching practices. Even though the observer is focused on assisting a colleague with instructional development, the observer should also be attuned to ways he or she can improve. This mutually beneficial process encourages instructors to take ownership of their own professional development in a collaborative environment. The goal is not to assess colleagues, but rather to support one another in their desire to refine their teaching skills.

The final step in this process is to provide a written summary. Both participants fill out a form that encourages them to focus on specific behaviors and words that promote effective teaching practices. They are both asked to reflect on what they learned through this process and how they will apply those insights to their teaching. These forms are added to the personnel files for the instructors.

\section{Discussion}

Through the CID process, the team discussed various issues that might arise. The key concern the team mentioned instructors might have was, “What happens if I’m observed on a day that goes poorly?” In an observation model where formative and summative evaluation occur simultaneously, this concern is very real, 
but in a model where the focus is solely on instructional development and the observation is viewed as one step in an instructor's journey to refine his or her craft, an "off day” can be seen more as an opportunity for growth than a situation to be feared.

On the flip side the primary concern the team thought observers might have was, "How do I respond in the post-observation meeting if the class I observed went poorly?” This situation can be uncomfortable for all observers, especially those who have little experience evaluating instructors or providing guided feedback to others. In this collaborative approach, the observer in this situation needs to think critically about the class, look for ways to encourage the instructor and prepare guided questions to help the instructor evaluate his or her own teaching.

This “most feared” situation occurred during one of the observations two members of the team had as they piloted this new process. These instructors describe what happened, how they thought about it as it happened and how they responded. It is clear through their experiences that the Collaborative Instructional Development process can be a positive, mutually beneficial approach to teacher development, even when things fail to go as planned.

\section{Reflections by Observer ${ }^{8}$}

\section{Pre-Observation Meeting}

I reviewed the questions for the Collaborative Instructional Development process before meeting with the teacher I planned to observe. Part of our meeting involved reviewing the lesson, which included SLOs as well as class activities. During the pre-observation, I asked questions about the sequencing, such as, "Why did you include two options for Socrative quizzes," and "Why do you have an option for Socrative and an option for Kahoot?” to get a feel for how she organized the lesson, her approach for teaching the materials, and her options for handling unexpected situations. It was clear she had thought through the lesson carefully, provided for an alternative option should anything go wrong, and allowed for scaffolding to walk students through the beginning research process. By the end of our discussion, I had a clear picture of what I was going to observe 
and on which areas the instructor wanted feedback: response time during questions, student/teacher balance during the class, and concept check questions utilized during class.

Because I also teach the course, I thought carefully about what I could glean from the initial observation experience to enrich my own teaching practice. Through this experiential process, I was open to finding techniques this teacher could share to enrich and inform my own teaching experience.

\section{Observation}

During the observation, I took objective notes over questions, times, student response time during questions, teacher responses to students, and language used for concept check questions during the class period. Later, I made notes to myself while I considered what happened during class. Since my task was to give feedback on specific aspects of the class, I focused my notes on those aspects.

While it was clear the students in the class were under-prepared for class, I was more interested in observing the instructor's response to this potentially disruptive issue than to assess students’ learning. To account for the students' lack of participation, the instructor utilized various methods to engage studentscalling on students by name, using technology gaming features, encouraging group participation, and monitoring participation by encouraging English language use in the classroom. The instructor was able to modify her plans to meet the students and move them forward in the research process. Although I could sense her frustration, it was clear that she had a plan to adjust for uncontrolled situations, such as incomplete homework and low class participation. Though my observation task was not to focus on her ability to adjust her teaching to unexpected events, because she demonstrated her ability to be flexible and maintain control in her classroom, I thought it important to note and later discuss during our post-observation meeting. We could then work together to create a strategy for classes that do not meet the teacher’s expectations in homework completion and classroom participation.

\section{Post-Observation Meeting}

During our post meeting, the instructor expressed frustration with the class. My response was positivewe learned something new. She managed an unexpected situation while maintaining control and presence in her 
class, and she was able to partially meet her outcomes in one period. We then discussed possibilities for such situations and the idea of having multiple back up plans so as not to disrupt the educational process. While meeting with the instructor, my focus was to ask reflective questions about her impressions of how the class went; I touched on the observation tasks she had requested, asked questions about her general impression of the classroom experience, and highlighted some of her seasoned teacher abilities in managing her classroom.

\section{Reflection}

I approach teacher (or peer) observations with empathy as a guide in identifying with teachers. After all, teaching, like writing, is a process in which we continually edit and revise our plans. Asking reflective questions seemed to ease the instructor and accelerate the conversation about the class. This process felt more organic than a traditional formative assessment. Additionally, I gave sincere feedback about positive, golden moments, which are indicative of a seasoned teaching professional. All the while, I was considering how working through challenging classroom situations informed my own practice. Being a part of someone else’s reflective teaching process clearly improved my own teaching; I stopped to take inventory of my own strengths and weaknesses during a fast-paced semester; my next lesson plan was stronger-carefully planned with alternatives to the main lesson, along with some ideas for improving participation in a fair, equitable manner.

From my perspective, the most effective and thoughtful planning comes from peer-to-peer interaction and observation of ideal and less-than-ideal teaching situations. Through this peer observation process, learning and sharing new teaching strategies, valuable critical moments, and different teaching styles became the focus of the process. As we move forward in developing more dynamic and reliable teaching practices to account for varied student populations, collaborating and growing with our peers is an essential part of the experience.

\section{Reflections by Instructor ${ }^{9}$}

During the Collaborative Instructional Development process, I was observed by a peer. The preobservation went smoothly as we discussed my lesson plan, the SLOs, my back-up plan in case something was not working as planned, and a little about the class and how the lesson fit within the semester. Most 
importantly, we discussed what aspects of my teaching that I want to improve on: improving the student/teacher balance during class and asking pointed questions checking comprehension spanning various levels of difficulty. A few days later, it was observation day. My students arrived on time and even two students who were not known for their attendance made an appearance. Then the bomb dropped - none of the students, not even the strong and reliable students, had completed their pre-class homework. This required plan C. I did not have a plan C. I went with plan B. I thought I could teach the material they were supposed to prepare for the course through the quiz. It did not work. They could not answer the questions. They were not focused and chose not to participate in any manner. The entire class felt like a train wreck. In addition to my lesson, I lectured them on the importance of completing homework and class participation. I warned them there would be the same quiz the following week. I left the class feeling defeated.

Another week passed before I met my observer for the post-observation meeting. It was amazing to see the class from her point of view. She did not see the train wreck I saw. Instead, she pointed out how calm I stayed under the pressure of a class that had not completed its work. Admittedly, during the observation, the SLO was only partially met, but it was met in the following class, which we were able to discuss as part of the meeting. My observer and I were able to exchange ideas about how to handle a class like this in the future and methods to prevent it. Instead of feeling like I was being judged and evaluated, we were able to work together to analyze the situation and make a plan to avoid this situation in the future. I learned from this process. I learned to not only see what went wrong but also to remember and reflect on what went right. Since this process is collaborative and with a peer, I was able to walk away from the post-observation meeting feeling better about the class I had originally thought to be a train wreck and I grew as an instructor.

\section{Conclusion}

The Collaborative Instructional Development process was created out of a need for professional growth and development as well as a need to have a formal observation in the personnel files of EAP instructors for the Center's evaluation purposes. The CID team worked together to create a process that would meet the needs of not only seasoned instructors but also new EAP instructors. It was imperative to create an instructor-driven 
observation protocol that allowed for both the instructor and observer to learn and grow. While the four-step process takes several hours to complete the time invested is worth it since this process provides a mutuallybeneficial, supportive experience for both participants. Because the process is more of a give and take between the instructor and the observer, the power is removed from the observer. The process is no longer evaluative in nature, which alleviates some of the pressure on each participant. Observers no longer have to worry about how to provide feedback to and write a formal assessment on a colleague whose class was less than stellar, and instructors no longer have to worry about how to "defend” themselves after a bad day in the classroom. The new observation process is, as its title states, collaborative. Each person involved should leave the postobservation meeting having learned and grown as an instructor with a new idea to apply to the classroom. The Collaborative Instructional Development process has the power to enhance and improve teaching in our language Center as instructors work together to support and encourage one another in their professional development.

\section{References}

Peer Review of Teaching. (2012). Retrieved April 24, 2017, from Cornell University Center for Teaching Excellence: http://www.cte.cornell.edu/resources/documenting-teaching/peer-review-ofteaching/index.html.

Teachers Observing Teachers: A Professional Development Tool for Every School. (2017). Retrieved April 24, 2017, from Education World: http://www.educationworld.com/a_admin/admin/admin297.shtml. 